\title{
ACCEPTED/IN PRESS
}

\section{COGNITION}

(C) 2016 American Psychological Association. This paper is not the copy of record and may not exactly replicate the authoritative document published in the APA journal. The final article will be available, upon publication, at:

DOI:

Accepted on 20/12/2018 


\section{Literacy improves short-term serial recall of spoken verbal but not visuospatial}

items - Evidence from illiterate and literate adults

Eleonore H.M. Smalle ${ }^{1,2,3}$, Arnaud Szmalec ${ }^{1,2,3}$, Louisa Bogaerts ${ }^{4}$, Mike P.A Page ${ }^{5}$, Vaishna Narang ${ }^{6}$, Deepshikha Misra ${ }^{6}$, Susana Araújo ${ }^{7}$, Nishant Lohagun ${ }^{6}$, Ouroz Khan $^{6}$, Anuradha Singh ${ }^{6}$, Ramesh K. Mishra ${ }^{8}$ and Falk Huettig 9

${ }^{1}$ Psychological Sciences Research Institute, Université catholique de Louvain, Louvain-la-Neuve, Belgium

${ }^{2}$ Institute of Neuroscience, Université catholique de Louvain, Brussels, Belgium

${ }^{3}$ Department of Experimental Psychology, Ghent University, Ghent, Belgium

${ }^{4}$ Department of Psychology, Hebrew University of Jerusalem, Jerusalem, Israel

${ }^{5}$ Department of Psychology, University of Hertfordshire, Hatfield, United Kingdom ${ }^{6}$ Jawaharlal Nehru University, New Delhi, India ${ }^{7}$ Department of Psychology, University of Lisbon, Portugal

${ }^{8}$ Centre for Neural and Cognitive Sciences, University of Hyderabad, Hyderabad, India

${ }^{9}$ Max Planck Institute for Psycholinguistics, Nijmegen, The Netherlands

\section{Correspondence Address}

Eleonore Smalle, $\mathrm{PhD}$

Université catholique de Louvain

Psychological Sciences Research Institute, Institute of Neuroscience

Place Cardinal Mercier 10, room C314

B-1348 Louvain-la-Neuve

E-mail: eleonore.smalle@uclouvain.be 


\begin{abstract}
It is widely accepted that specific memory processes, such as serial-order memory, are involved in written language development and predictive of reading and spelling abilities. The reverse question, namely whether orthographic abilities also affect serial-order memory, has hardly been investigated. In the current study, we compared 20 illiterate people with a group of 20 literate matched controls on a verbal and a visuospatial version of the Hebb paradigm, measuring both short- and long-term serial-order memory abilities. We observed better short-term serial-recall performance for the literate compared with the illiterate people. This effect was stronger in the verbal than in the visuospatial modality, suggesting that the improved capacity of the literate group is a consequence of learning orthographic skills. The long-term consolidation of ordered information was comparable across groups, for both stimulus modalities. The implications of these findings for current views regarding the bidirectional interactions between memory and written language development are discussed.
\end{abstract}

Key words: written language development, illiteracy, Hebb repetition learning, shortterm memory, serial order 
The human ability to temporarily retain ordered sequences of verbal information has evolved with the core purpose of developing linguistic representations that can be accessed during (spoken and written) language production and comprehension (Baddeley, Gathercole, \& Papagno, 1988). Numerous studies with both children and adults have found strong associations between performance on verbal immediate serial-recall tasks (e.g., digit span tasks) and vocabulary acquisition. This suggests that verbal short-term memory, and in particular short-term memory for serial-order information, not item information (Majerus \& Boukebza, 2013; Ordonez-Magro, Attout, Szmalec \& Majerus, 2018; Romani, Tsouknida, \& Olson, 2015), supports lexical development (Gathercole, Service, Hitch, Adams, \& Martin, 1999; Gathercole, 2006; Gupta, 2003; Page \& Norris, 2009). More directly, Szmalec and colleagues found that repetitive immediate serial recall of syllable sequences creates long-term representations of novel word-forms in the mental lexicon (Szmalec, Duyck, Vandierendonck, Mata, \& Page, 2009; Szmalec, Page, \& Duyck, 2012).

There is also substantial experimental evidence for the predictive role of verbal memory capacity in written language acquisition (Gathercole, Alloway, Willis, \& Adams, 2006; Alloway \& Alloway, 2010; Nevo \& Bar-Kochva, 2015; Martinez Perez, Majerus, \& Poncelet, 2012). Specifically, the short-term retention of verbal serial-order information has been found to play a role in the development of reading and spelling (dis)abilities (Swanson, Xinhua, \& Jerman, 2009; Martinez Perez, Majerus, Mahot, \& Poncelet, 2012; Hachmann et al., 2014; Romani et al., 2015; Romani, Di Betta, Tsouknida, \& Olson, 2008). Some studies have also found that the ability to learn sequences from repetition is impaired in individuals with dyslexia (Bogaerts, Szmalec, Hachmann, Page, \& Duyck, 2015; Szmalec, Loncke, Page, \& Duyck, 2011) and is predictive for early written language development (Bogaerts, 
Szmalec, De Maeyer, Page, \& Duyck, 2016). These observations are not surprising if we consider that the task for a beginning reader is to learn to decode novel orthographic representations (letters/graphemes) into sequences of phonemes (Szmalec, 2018). This first happens by temporarily storing each corresponding phoneme and its serial position in short-term memory until the entire orthographic structure is processed. With practice, grapheme-to-phoneme decoding automatizes, possibly through implicit Hebbian learning processes (Hebb, 1961), so that the reader eventually gets direct access to a unitized phonological representation. At the same time, a beginner reader learns to spell/write, that is, to transform phonological representations of words into their corresponding orthographic representations (Schoonbaert \& Grainger, 2004). Spelling might be considered more strongly dependent on serial processing in memory because it is time-consuming and continuously requires explicitly serial processes even when unitized orthographic representations are retrieved from memory (Romani et al., 2015). In sum, learning to read and spell in non-logographic (e.g., alphabetic, alphasyllabic, or syllabic) writing systems is assumed to crucially rely on the capacity to maintain in the short term, and then to consolidate into memory, sequential verbal information.

Recently, Demoulin and Kolinsky (2016) discussed the extent to which learning a writing system might shape memory, arguing for a potential opposite causal relationship between reading/spelling and serial-order memory, from that traditionally assumed. Indeed, the intensive practice of recoding skills during written language development might support the development of memory functions such as subvocal rehearsal and, consequently, short-term memory for serial-order information. Although the influence of memory on orthographic skills has been widely 
investigated, the impact of these skills on verbal short-term serial recall has not yet received rigorous experimental testing.

An interesting approach to experimentally investigating how written language development can shape memory is by comparing memory performance of literate people with that of people who never learned to read/write, and therefore lack knowledge of grapheme-phoneme correspondences (Huettig \& Mishra, 2014). In 2012, Silva and colleagues explored this by comparing illiterate people to a group of age-matched literate controls on a battery of verbal and nonverbal working memory tasks. They found a literacy effect on a verbal version of a forward span task, but not on its spatial variant (Silva, Faisca, Ingvar, Petersson, \& Reis, 2012). Together with previous findings showing literacy effects on pseudo-word repetition (e.g., Petersson, Reis, \& Ingvar, 2001; Kosmidis, Tsapkini, \& Folia, 2006; Kosmidis, Zafiri, \& Politimou, 2011), their results suggest that alphabetic knowledge influences shortterm retention capacities within the phonological loop. This influence might be mediated by explicit phonological processing abilities, such as phonological awareness, that are enhanced through reading and spelling (e.g., Castro-Caldas et al., 1998).

In the present work, we were interested in the extent to which literacy shapes memory for serial-order. We aimed to test whether literate individuals have stronger short- and long-term memory capacities for verbal and visuospatial serial information. We compared a group of illiterate individuals to a group of age-matched literate individuals on a verbal and visuospatial version of the Hebb task (Hebb, 1961), a task that measures short- and long-term serial-memory abilities. In this task, sequences of items are presented for immediate serial recall. After presentation, the participants are required to recall the items in the order of presentation. For certain sequences, called 
Hebb sequences, the items are presented in exactly the same order every $\mathrm{n}^{\text {th }}$ trial, while for other sequences, called filler sequences, items are presented in a different order on each occasion. The difference in recall performance for the two sequence types (i.e., Hebb repetition effect or HRE) reflects a process of long-term memorization of the repeated sequences. As such, serial-order processing in shortterm memory and the transfer of serial-order information into long-term memory can be measured within the same task. Importantly, the items are provided during recall so that only the order of the items needs to be reproduced. This is an important distinction to previous studies using digit span or nonword repetition tasks that require the retrieval of both item and order information and therefore do not allow such a precise assessment of serial-order memory capacity (Hurlstone, Hitch, \& Baddeley, 2014).

Based on the assumption that recoding skills developed in literacy permit some practice of the temporary encoding of the serial order of phonemes and graphemes (Demoulin \& Kolinsky, 2016), we predicted that literate participants would perform better than the illiterate participants on recalling the order of the verbal items. In other words, we predicted a literacy effect on overall recall performance for the verbal Hebb task, but not necessarily for the visuospatial variant. We had no specific predictions for the effect of literacy on the long-term serial-order consolidation of the sequences, as measured by the HRE, though one might make a case for larger effects in the literate group, either due to better encoding capacities in short-term memory, or possibly because storing lexical representations in long-term memory is crucial for fast and accurate reading/spelling of irregular words, such that long-term learning itself is affected by orthographic skills. 


\section{Method}

\subsection{Participants}

Twenty illiterate and twenty age-matched literate people, all female, participated after informed consent was obtained ${ }^{1}$. All participants came from the same informal settlement in New Delhi, India, and had a similar socioeconomic background. None showed signs of neurological disease or cognitive deficits. Participants underwent a semi-structured interview that probed their level of schooling, the reasons for receiving formal education or not, their profession and monthly income. In order to ensure that the illiterate participants did not have any literacy knowledge, all were screened with a syllabo-graphic knowledge test (testing recognition of the 44 aksharas of the Devanagari script) and a word-reading test (testing the ability to read 75 Devanagari words of varying syllabic complexity). Table 1 shows that, as expected, the two groups differed considerably on the akshara knowledge and word-reading tests. The groups also differed in their score on the Raven's test of non-verbal intelligence (Raven, Raven, \& Court, 2000). This is a common finding in studies comparing literate and illiterate people (e.g., Olivers, Huettig, Singh, \& Mishra, 2014) as performance on this task is affected by formal education (Neisser et al., 1996).

\subsection{Stimuli, design and procedure}

All participants were tested in a secluded room in front of a laptop with 15.6inch screen and 1024x768 resolution, running E-prime 2.0 (Psychology Software Tools, Inc.). Prior to the experiment, participants were tested on their knowledge of 32 monosyllabic spoken Hindi words in a word-to-picture matching task

\footnotetext{
1 The illiterate group came from a larger pool of 91 illiterate participants that took part in an ongoing longitudinal study with a different purpose.
} 
(Supplementary Materials). In a second session that took place on a separate day, participants performed both Hebb tasks. The order of task modality was randomized.

\subsubsection{Verbal Hebb learning}

The Hebb learning procedure was adapted from Bogaerts et al. (2016). Four different sets of six words were created out of the original set of 32 words (Supplementary Materials). In total, 32 sequences were presented. This included three different Hebb sequences, each constructed from a different item-set, that were each repeated eight times (every $4^{\text {th }}$ to $6^{\text {th }}$ trial), interspersed with eight filler sequences comprising a random ordering of a fourth set. ${ }^{2}$

On each trial, a sequence of six monosyllabic Hindi words was presented auditorily, followed by a visual recall screen showing the six black and white drawings corresponding to the words (Figure 1). Participants were asked to reconstruct the sequence of auditory words by clicking on the corresponding drawings in the order their labels had appeared. The drawings changed color (from black to grey) when clicked. After all six drawings were clicked the participant pressed the space bar to continue to the following trial. The dependent measure was the average number of items recalled in the correct serial position of each sequence (max. 6).

\subsubsection{Visuospatial Hebb learning}

The procedure was similar to the verbal Hebb task described above. Four different pad configurations (Supplementary Materials) were created and used as Filler, Hebb 1, Hebb 2, Hebb 3 in a Latin-square order, counterbalanced across

\footnotetext{
2 In contrast to the more traditional Hebb learning procedure with a single repeating Hebb sequence, we decided to present three different repeating Hebb sequences (e.g., Saint-Aubin \& Guérard, 2017) for psychometric reasons, i.e. to obtain a more reliable measure for individual performance on the long-term learning process (Bogaerts, Siegelman, Ben-Porat, \& Frost, 2018).
} 
participants. Each trial consisted of six images of a brown lily pad and a green frog presented on the screen. During each trial, the frog jumped from one lily pad to another (Figure 2), with a 1000ms interval. After arriving on the sixth lily pad, the frog disappeared, and participants were asked to click the lily pads in the order that was followed by the frog. The lily pads changed color (from dark to light brown) when clicked. The dependent variable was the average number of pads recalled in the correct serial position of each sequence (max. 6).

\section{Results}

Recall accuracy was averaged across the three within-modality Hebb sequences for each participant and compared with recall accuracy for the filler sequences. As illustrated in Figure 3, the individual trial scores for each sequence type were collapsed into first-half (i.e., first four trials) and second-half (i.e., final four trials) scores. A mixed-factorial analysis with all factors was conducted, and all Ftests are reported (Table 2). In addition, we report Bayes factors ${ }^{3}$ for Group effects (Table 3). Data were analyzed using JASP software (2014, version 0.8.4.0) and we relied on the guidelines proposed by Jeffreys (1961) for interpreting the Bayes factors.

The results showed a main effect of Group with decisive evidence. The immediate serial-recall performance was better in literate compared with illiterate people. This effect differed, with strong evidence, as a function of Task Modality.

\footnotetext{
${ }^{3}$ Bayes factors serve as estimations of how likely the observed data are to arise under the testing hypothesis (that there is a Group effect) relative to the null hypothesis (no Group effect) (i.e., $\left.\mathrm{BF}_{10}=\mathrm{P}[\mathrm{data} \mid \mathrm{Ha}] / \mathrm{P}[\mathrm{data} \mid \mathrm{H} 0]\right)$ (Jarosz \& Wiley, 2014). Hence, small values $\left(\mathrm{BF}_{10}\right.$ $<1)$ indicate that there is more evidence for the null hypothesis, and large values $\left(\mathrm{BF}_{10}>1\right)$ indicate more evidence for the alternative hypothesis. Evidence is calculated as the sum of $\mathrm{P}(\mathrm{M} \mid$ data $)$ of the models with the effect of interest divided by the sum of $\mathrm{P}(\mathrm{M} \mid \mathrm{data})$ of the models without the specific effect. These estimates are available in JASP (>0.8.2.0) under inclusion Bayes factors on matched models, resulting in BF inclusion scores (see Table 3).
} 
More specifically, there was a reliable group difference in the verbal while not in the visuospatial modality.

There was also a main effect of Sequence Type in favor of the repeating Hebb sequence. This interacted with Half ${ }^{4}$. Planned comparisons showed reliable improvements across halves for the Hebb but not for the Filler sequences. Importantly, this HRE was significantly weaker in the visuospatial modality as opposed to the verbal modality, evidenced by a reliable 3-way interaction between Sequence Type, Modality and Half. While in the verbal modality alone the size of the Hebb-advantage increased across the two halves, evidenced by a reliable Sequence by Half interaction, this was not the case for the equivalent interaction term for the visuospatial modality. Hebb learning did not differ as a function of Group (i.e., no significant Sequence Type $\mathrm{x}$ Half $\mathrm{x}$ Group interaction), and the $\mathrm{BF}_{\text {inclusion }}=0.235$ for this effect provides substantial evidence in favor of the null hypothesis.

\section{Discussion}

The present study addressed the question of whether literacy may influence the ability to represent serial-order information in human memory. This was tested by using a well-established paradigm in the memory literature that measures short- and long-term memory for sequential information through repeated immediate recall. A group of illiterate and literate individuals was tested on a verbal and visuospatial Hebb task. We were interested in measuring illiterate people's capacity to temporarily

\footnotetext{
${ }^{4}$ Please note that while a main effect of Sequence type in favour of the Hebb sequence might provide some evidence of learning the repeated sequence, only the demonstration of an interaction between Sequence Type and Half, reflecting improvement across halves on the Hebb sequences but not on the filler sequences, is usually accepted as evidence of long-term consolidation of the Hebb sequence (see also, Mosse \& Jarrold, 2008; Archibald \& Joanisse, 2013; Smalle et al., 2015; Henderson \& Warmington, 2017).
} 
retain verbal sequential information in short-term memory, given that this might be enhanced by recoding abilities that are practiced with reading and spelling. We also investigated people's ability to consolidate short-term memory representations as a function of repeated exposure. Overall, we found that the literate participants showed better immediate recall for the sequences than the illiterate participants, specifically for the verbal modality. There were no reliable group differences for the long-term Hebb learning of the sequences, and this for either modality. The results are in line with the hypothesis put forward by Demoulin and Kolinsky (2016) that orthographic knowledge significantly modulates the ability to process verbal serial-order information in short-term memory.

It is important to note that we found a literacy advantage on short-term serial recall performance that is larger for verbal than for visuospatial materials. The few previous studies that investigated the influence of literacy on memory performance also found that literacy particularly modulates short-term retention of phonological information such as found with digit span and nonword repetition tasks (e.g., Silva et al., 2012; Peterson et al., 2001), while not, or to a much lesser extent, with spatialspan tasks (e.g., Swanson et al., 2009). As discussed earlier, performance on verbal tasks correlates with children's reading and word-learning achievements, indicating that the phonological loop is an integral part of the child's literacy development. Here, we observed modality-specificity of short-term memory for serial-order information ${ }^{5}$,

\footnotetext{
${ }^{5}$ In the visuospatial task, participants were required to memorize the temporal order of spatial locations followed by a frog while the spatial alignment of the locations remained visible. This means that task performance relied on serial order encoding similar to the verbal variant of the task, and not on spatial order encoding (i.e. remembering the path as an integrated pattern). Previous research by Parmentier, Elford and Mayberry (2005) showed that spatial paths such as used in the present task affect serial recall performance as is the case in verbal serial memory. In the present study, we observe primacy effects (i.e. better recall for the first positions in the path) in the visuospatial task (similar to the verbal task; see supplementary
} 
which is in line with the assumption that the orthographic decoding skills developed through literacy permit practicing and strengthening the temporary encoding of phoneme and grapheme sequences, and as a consequence, improving serial-order processing in verbal, more than in visuospatial memory (Demoulin \& Kolinsky, 2016).

We found equivalent repetition-learning for literate and illiterate groups. This finding contributes to a recent debate about serial-order processing deficits in developmental disorders such as dyslexia. A majority of these studies found that the long-term consolidation of serial-order information such as measured by the HRE is altered in dyslexia (e.g., Hedenius et al., 2013; Bogaerts et al., 2015; Henderson \& Warmington, 2017; but see Staels et al., 2015). Some authors have found that the effect is not specific to the verbal modality, but also slightly affects the long-term memorization of visuospatial sequences (Szmalec et al., 2011; Romani et al., 2015). The observation that long-term Hebb repetition learning of serial-order information is impaired in dyslexia but not in illiterate people is therefore interesting and confirms a qualitative dissociation between illiteracy and reading/spelling impairment. While both dyslexic and illiterate people seem to have problems with the capacity to retain sequences in short-term verbal memory, only dyslexic people seem to have additional problems with the long-term learning of sequential information. This might be a consequence, therefore, of automatization deficits associated with the developmental disorder (Elliott \& Nicolson, 2016), and not a mere effect of lack of training on reading or spelling (cf. Huettig, Lachmann, Reis, \& Petersson, 2017). 


\subsection{Limitations and considerations}

In the present data, recall for the repeating visuospatial sequences did not improve across the two halves of the task, for either group. Our averaged recall scores were comparable between the two task-modalities suggesting that the null finding for learning cannot be explained by a floor-effect for recalling visuospatial sequences. One alternative explanation concerns the amount of item-overlap that exists for the visuospatial relative to verbal sequences. In the verbal task all sequences consist of different words causing minimal interference. However, due to the limited range of coordinates that can be used across the visual display, the visuospatial sequences are built of (semi-)overlapping coordinates. Item-overlap has been shown to slow down or even completely abolish sequence learning, resulting in significantly weaker or no HREs (Page et al., 2013; Smalle et al., 2015; Johnson, Dygacz \& Miles, 2017).

A significant body of research has demonstrated that literacy and formal schooling influences the visual skills needed to perform successfully on nonverbal intelligence tests (cf. Neisser et al., 1999). We think it is unlikely that the results in the present study are caused by differences in nonverbal intelligence (other than related to literacy). This is further supported by an exploratory analysis (Supplementary Materials) in which we compared IQ-matched subgroups and again reveal a specific effect of literacy on (verbal) serial-recall performance. This would not be predicted on the assumption of lower (nonverbal) intelligence in the illiterates.

\subsection{Conclusion}

Taken together, the present findings substantiate the hypothesis that learning to read and write significantly influences human cognition and, in particular, memory for serial order. Specifically, the capacity to temporarily memorize verbal serial-order 
information seems to be influenced by the prior acquisition of orthographic skills underlying reading and spelling. In contrast, short-term memory for visuospatial order-information and long-term learning of sequential information in general, seem to be less affected by literacy, despite the fact that other visual skills, such as those found in nonverbal intelligence tests, are affected. These novel findings have some important implications for the role of literacy in the development of those serialmemory processing abilities that play an important role in human behavior, beyond just language.

\section{Acknowledgements}

This research was funded by Max Planck Society Strategic Innovation grant M.FE.A.PSYL0004 awarded to FH.

\section{Declaration of conflict of interest}

None

\section{Data Availability}

The datasets generated and analyzed during the current study are available via osf.io/w2bft 


\section{References}

Alloway, T. P., \& Alloway, R. G. (2010). Investigating the predictive roles of working memory and IQ in academic attainment. Journal of Experimental Child Psychology, 106(1), 20-29. doi:10.1016/j.jecp.2009.11.003

Archibald, L.M.D., \& Joanisse, M.F. (2013). Domain-specific and domain-general constraints on word and sequence learning. Memory and Cognition, 41(2), 268-280. doi:

$$
10.3758 / \mathrm{s} 13421-012-0259-4
$$

Baddeley, A., Gathercole, S., \& Papagno, C. (1998). The phonological loop as a language learning device. Psychological Review, 105(1), 158.

Bogaerts, L., Szmalec, A., De Maeyer, M., Page, M. P., \& Duyck, W. (2016). The involvement of long-term serial-order memory in reading development: A longitudinal study. Journal of Experimental Child Psychology, 145, 139-156. doi:10.1016/j.jecp.2015.12.008

Bogaerts, L., Szmalec, A., Hachmann, W., Page, M. P., \& Duyck, W. (2015). Linking memory and language: Evidence for a serial-order learning impairment in dyslexia. Research in Developmental Disabilities, 43-44, 106-122. doi:10.1016/j.ridd.2015.06.012

Bogaerts, L., Siegelman, N., Ben-Porat, T., \& Frost, R. (2018). Is the Hebb repetition task a reliable measure of individual differences in sequence learning? The Quarterly Journal of Experimental Psychology, 1-35. doi:10.1080/17470218.2017.1307432

Byrd, D. A., Jacobs, D. M., Hilton, H. J., Stern, Y., \& Manly, J. J. (2005). Sources of errors on visuoperceptual tasks: Role of education, literacy, and search strategy. Brain and Cognition, 58(3), 251-257. doi:10.1016/j.bandc.2004.12.003

Castro-Caldas, A., Petersson, K. M., Reis, A., Stone-Elander, S., \& Ingvar, M. (1998). The illiterate brain: Learning to read and write during childhood influences the functional 
organization of the adult brain. Brain, 121 (Pt 6), 1053-1063.

doi:10.1093/brain/121.6.1053

Demoulin, C., \& Kolinsky, R. (2016). Does learning to read shape verbal working memory? Psychonomic Bulletin \& Review, 23(3), 703-722. doi:10.3758/s13423-015-0956-7

Elliott, J., \& Nicolson, R. (2016). Dyslexia: Developing the Debate. Bloomsbury Publishing. Gathercole, S. E. (2006). Nonword repetition and word learning: The nature of the relationship. Applied Psycholinguistics, 27(04), 513-543. doi:10.1017/S0142716406060383

Gathercole, S. E., Alloway, T. P., Willis, C., \& Adams, A.-M. (2006). Working memory in children with reading disabilities. Journal of Experimental Child Psychology, 93(3), 265281. doi:10.1016/j.jecp.2005.08.003

Gathercole, S. E., Service, E., Hitch, G. J., Adams, A. M., \& Martin, A. J. (1999). Phonological short-term memory and vocabulary development: further evidence on the nature of the relationship. Applied Cognitive Psychology, 13(1), 65-77.

Gupta, P. (2003). Examining the relationship between word learning, nonword repetition, and immediate serial recall in adults. Quarterly Journal of Experimental Psychology, 56(7), 1213-1236. doi:10.1080/02724980343000071

Hachmann, W. M., Bogaerts, L., Szmalec, A., Woumans, E., Duyck, W., \& Job, R. (2014). Short-term memory for order but not for item information is impaired in developmental dyslexia. Annals of Dyslexia, 64(2), 121-136. doi:10.1007/s11881-013-0089-5

Hebb, D. O. (1961). Brain mechanisms and learning. In J. F. Delafresnaye (Ed.), Distinctive features of learning in the higher animal (pp. 37-46). New York: Oxford University Press.

Hedenius, M., Persson, J., Alm, P. A., Ullman, M. T., Howard, J. H., Jr., Howard, D. V., \& Jennische, M. (2013). Impaired implicit sequence learning in children with developmental 
dyslexia. Research in Developmental Disabilities, 34(11), 3924-3935.

doi:10.1016/j.ridd.2013.08.014

Henderson, L. M., \& Warmington, M. (2017). A sequence learning impairment in dyslexia? It depends on the task. Research in Developmental Disabilities, 60(Supplement C), 198210. doi:10.1016/j.ridd.2016.11.002

Huettig, F., Lachmann, T., Reis, A., \& Petersson, K. M. (2017). Distinguishing cause from effect - many deficits associated with developmental dyslexia may be a consequence of reduced and suboptimal reading experience. Language, Cognition and Neuroscience, 1-18. doi:10.1080/23273798.2017.1348528

Huettig, F., \& Mishra, R. K. (2014). How literacy acquisition affects the illiterate mind-a critical examination of theories and evidence. Language and Linguistics Compass, 8(10), 401427. doi:10.1111/lnc3.12092

Hurlstone, M. J., Hitch, G. J., \& Baddeley, A. (2014). Memory for serial order across domains: An overview of the literature and directions for future research. Psychological Bulletin, 140(2), 339-373. doi:10.1037/a0034221

Jarosz, A. F., \& Wiley, J. (2014). What are the odds? A practical guide to computing and reporting Bayes Factors. The Journal of Problem Solving, 7(1). doi:10.7771/19326246.1167

JASP. (2014). Retrieved from http://jasp-stats.org/.

Jeffreys, H. (1961). Theory of probability (3 ed.). Oxford: Oxford University Press, Clarendon Press.

Johnson, A. J., Dygacz, A., \& Miles, C. (2017). Hebb repetition effects for non-verbal visual sequences: Determinants of sequence acquisition. Memory, 25(9), 1279-1293. doi:10.1080/09658211.2017.1293692 
Kosmidis, M. H., Tsapkini, K., \& Folia, V. (2006). Lexical Processing in Illiteracy: Effect of Literacy or Education? Cortex, 42(7), 1021-1027. doi:10.1016/S0010-9452(08)70208-9

Kosmidis, M. H., Zafiri, M., \& Politimou, N. (2011). Literacy versus formal schooling: Influence on working memory. Archives in Clinical Neuropsychology, 26(7), 575-582. doi:10.1093/arclin/acr063

Majerus, S., \& Boukebza, C. (2013). Short-term memory for serial order supports vocabulary development: New evindence from a novel word learning paradigm. Journal of Experimental Child Psychology, 116(4), 811-828.

Martinez Perez, T., Majerus, S., \& Poncelet, M. (2012). The contribution of short-term memory for serial order to early reading acquisition: Evidence from a longitudinal study. Journal of Experimental Child Psychology, 111(4), 708-723. doi:10.1016/j.jecp.2011.11.007

Martinez Perez, T., Majerus, S., Mahot, A., \& Poncelet, M. (2012b). Evidence for a specific impairment of serial order short-term memory in dyslexic children. Dyslexia, 18(2), 94109. doi:10.1002/dys.1438

Mosse, E. K., \& Jarrold, C. (2008). Hebb learning, verbal short-term memory, and the acquisition of phonological forms in children. Quarterly Journal of Experimental Psychology, 61(4), 505-514. doi:10.1080/17470210701680779

Neisser, U., Boodoo, G., Bouchard Jr, T. J., Boykin, A. W., Brody, N., Ceci, S. J., . . Sternberg, R. J. (1996). Intelligence: Knowns and unknowns. American psychologist, 51(2), 77. doi:10.1037/0003-066X.51.2.77

Nevo, E., \& Bar-Kochva, I. (2015). The Relations Between Early Working Memory Abilities and Later Developing Reading Skills: A Longitudinal Study From Kindergarten to Fifth Grade. Mind, Brain, and Education, 9(3), 154-163. doi:10.1111/mbe.12084 
Ordonez Magro, L., Attout, L., Szmalec, A., \& Majerus, S. (2018). Short-and long-term memory determinants of novel word form learning. Cognitive Development, 47, 146-157. doi:10.1016/j.cogdev.2018.06.002

Page, M. P. A., \& Norris, D. (2009). A model linking immediate serial recall, the Hebb repetition effect and the learning of phonological word forms. Philosopical Transactions of the Royal Society B: Biological Sciences, 364(1536), 3737-3753. doi:10.1098/rstb.2009.0173

Page, M. P. A, Cumming, N., Norris, D., McNeil, A.M., \& Hitch., G.J. (2103). Repetitionspacing and item-overlap effects in the Hebb repetition task. Journal of Memory and Language, 69(4), 506-526. doi: 10.1016/j.jml.2013.07.001

Parmentier, F.B.R., Elford, G., \& Mayberry, M. (2005). Transitional information in spatial serial memory: Path characterisitics affect recall performance. Journal of Experimental Psychology: Learning, memory and cognition, 31(3): 412-427. doi: 10.1037/02787393.31.3.412

Petersson, K. M., Reis, A., \& Ingvar, M. (2001). Cognitive processing in literate and illiterate subjects: A review of some recent behavioral and functional neuroimaging data. Scandinavian Journal of Psychology, 42(3), 251-267. doi:10.1111/1467-9450.00235

Psychology Software Tools, Inc. [E-Prime 2.0]. (2016). Retrieved from http://www.pstnet.com.

Olivers, C., Huettig, F., Singh, J., \& Mishra, R. (2014). The influence of literacy on visual search. Visual Cognition, 22(1), 74-101. doi:10.1080/13506285.2013.875498

Raven, J., Raven, J. C., \& Court, J. H. (2000). Standard progressice matrices. Oxford: Psychology Press.

Romani, C., Di Betta, A. M., Tsouknida, E., \& Olson, A. (2008). Lexical and nonexical processing in developmental dyslexia: A case for different resources and different 
impairments. Cognitive Neuropsychology, 25(6), 798-830. doi:

\section{$10.1080 / 02643290802347183$}

Romani, C., Tsouknida, E., \& Olson, A. (2015). Encoding order and developmental dyslexia: A family of skills predicting different orthographic components. The Quarterly Journal of Experimental Psychology, 68(1), 99-128. doi: 10.1080/17470218.2014.938666

Saint-Aubin, J., \& Guérard, K. (2017). The Hebb Repetition Effect as a Laboratory Analogue of Language Acquisition: Learning Three Lists at No Cost. Canadian Journal of Experimental Psychology, 72(1), 2. doi:10.1037/cep0000136

Schoonbaert, S., \& Grainger, J. (2004). Letter position coding in printed word perception: Effects of repeated and transposed letters. Language and Cognitive Processes, 19(3), 333-367. doi: $\underline{10.1080 / 01690960344000198}$

Silva, C., Faisca, L., Ingvar, M., Petersson, K. M., \& Reis, A. (2012). Literacy: Exploring working memory systems. Journal of Clinical Experimental Neuropsychology, 34(4), 369-377. doi:10.1080/13803395.2011.645017

Smalle, E. H. M., Bogaerts, L., Simonis, M., Duyck, W., Page, M. P. A., Edwards, M. G., \& Szmalec, A. (2015). Can Chunk Size Differences Explain Developmental Changes in Lexical Learning? Frontiers in Psychology, 6, 1925. doi: 10.3389/fpsyg.2015.0192

Staels, E., \& Van den Broeck, W. (2014). Order short-term memory is not impaired in dyslexia and does not affect orthographic learning. Frontiers in Human Neuroscience, 8, 732. doi: $\underline{10.3389 / \text { fnhum.2014.00732 }}$

Staels, E., \& Van den Broeck, W. (2015). No solid empirical evidence for the solid (serial order learning impairment) hypothesis of dyslexia. Journal of Experimental Psychology: Learning, Memory, and Cognition, 41(3), 650. doi:10.1037/xlm0000054 
Swanson, H. L., Xinhua, Z., \& Jerman, O. (2009). Working memory, short-term memory, and reading disabilities: A selective meta-analysis of the literature. Journal of Learning Disabilities, 42(3), 260-287. doi:10.1177/0022219409331958

Szmalec, A., Duyck, W., Vandierendonck, A., Mata, A. B., \& Page, M. P. (2009). The Hebb repetition effect as a laboratory analogue of novel word learning. Quarterly Journal of Experimental Psychology, 62(3), 435-443. doi:10.1080/17470210802386375

Szmalec, A., Loncke, M., Page, M. P. A., \& Duyck, W. (2011). Order or disorder? Impaired Hebb learning in dyslexia. Journal of Experimental Psychology: Learning, Memory, and Cognition, 37(5), 1270-1279. doi:10.1037/a0023820

Szmalec, A., Page, M. P. A., \& Duyck, W. (2012). The development of long-term lexical representations through Hebb repetition learning. Journal of Memory and Language, 67(3), 342-354. doi:10.1016/j.jml.2012.07.001

Szmalec, A. (2018). Mémoire et apprentisages chez les personnes dyslexiques. In: Les dyslexies. France : Elsevier Masson.

Trecy, M. P., Steve, M., \& Martine, P. (2013). Impaired short-term memory for order in adults with dyslexia. Research in Developmental Disabilities, 34(7), 2211-2223. doi: $\underline{10.1016 / j . r i d d .2013 .04 .005}$ 
Table 1. Participant characteristics

\begin{tabular}{lll}
\hline & Literates $(\mathrm{n}=20)$ & Illiterates $(\mathrm{n}=20)$ \\
\hline Mean age (yrs) & $24.3(18-38)$ & $25.7(18-30)$ \\
Sex & $\mathrm{F}=20$ & $\mathrm{~F}=20$ \\
Monthly income (in Rupees) & $2377(700-4000)$ & $2122(857-3428)$ \\
No. of persons in family & $5.4(3-9)$ & $4.58(3-9)$ \\
No. of earning family members & $1.5(1-4)$ & $1.5(1-4)$ \\
Family Income (in Rupees) & $10735(3.5 \mathrm{~K}-24 \mathrm{~K})$ & $10 \mathrm{~K}(5 \mathrm{~K}-24 \mathrm{~K})$ \\
Years of schooling & $12.5(10-15)$ & $0.5(0-4)^{* * *}$ \\
Raven's Progressive Matrices, raw/60 & $36(16-52)$ & $17 / 60(7-35)^{* * *}$ \\
Word reading scores, raw/75 & $73.3(68-75)$ & $0.8(0-7)^{* * *}$ \\
Akshara knowledge scores, raw/44 & $43.5(40-44)$ & $1.7(0-14)^{* * *}$ \\
\hline p $<0.05 ; * \mathrm{p}<0.01 ; * * \mathrm{p}<0.001$ & &
\end{tabular}

Table 2. Repeated Measures ANOVA with factors Group (literate vs. illiterate), Task Modality (verbal vs. visuospatial), Sequence Type (Filler vs. Hebb), Half (first-half vs. second-half); $\operatorname{Df}(1,38)$.

\begin{tabular}{llc}
\hline Effects & $F$ & $n^{2}{ }_{p}$ \\
\hline Group & $17.7 * * *$ & .317
\end{tabular}




\begin{tabular}{|c|c|c|}
\hline Task Modality & $<1$ & -- \\
\hline Task Modality x Group & $3.56^{\circ}$ & 0.086 \\
\hline Verbal: Group & $31.7 * * *$ & .455 \\
\hline Visuospatial: Group & 3.31 & .080 \\
\hline Sequence Type & $23.7 * * *$ & 0.384 \\
\hline Sequence Type x Group & $<1$ & -- \\
\hline Half & $5.4^{*}$ & 0.124 \\
\hline Half x Group & $<1$ & --- \\
\hline Task Modality x Sequence Type & 3.14 & -- \\
\hline Task Modality x Sequence Type x Group & $<1$ & -- \\
\hline Task Modality x Half & 1.25 & -- \\
\hline Task Modality x Half x Group & $<1$ & -- \\
\hline Sequence Type x Half & $10.0 * *$ & 0.208 \\
\hline Hebb: Half & $22.5^{* * *}$ & .372 \\
\hline Filler: Half & $<1$ & -- \\
\hline Sequence Type x Half x Group & $<1$ & -- \\
\hline Task Modality x Sequence Type x Half & $4.7 *$ & 0.110 \\
\hline Verbal: Sequence Type x Half & $13.6 * * *$ & .264 \\
\hline Visuospatial: Sequence Type x Half & $<1$ & -- \\
\hline Task Modality x Sequence Type x Half x Group & $<1$ & -- \\
\hline
\end{tabular}

Table 3. Bayesian Repeated Measures ANOVA: Specific effects

\begin{tabular}{llll}
\hline Effects & $\mathrm{P}($ incl $)$ & $\mathrm{P}($ incl|data $)$ & $\mathrm{BF}_{\text {inclusion }}$ \\
\hline Group & 0.114 & 0.117 & 142.22 \\
Task Modality x Group & 0.299 & 0.813 & 27.142 \\
$\quad$ Verbal: Group & 0.263 & 0.584 & 8483.12
\end{tabular}


Visuospatial: Group

0.263

0.491

$0.114 \quad 0.004$

0.235

Sequence Type x Half x Group

0.114

Task Modality x Sequence Type x 0.006

$2.612 \mathrm{e}-6$

0.266

\section{Half x Group}

Note: $\mathrm{P}(\mathrm{incl})=$ prior inclusion probability; $\mathrm{P}($ incl $\mid$ data $)=$ posterior inclusion probabilities; $\mathrm{BF}_{\text {inclusion }}=$ change from prior to posterior inclusion odds 


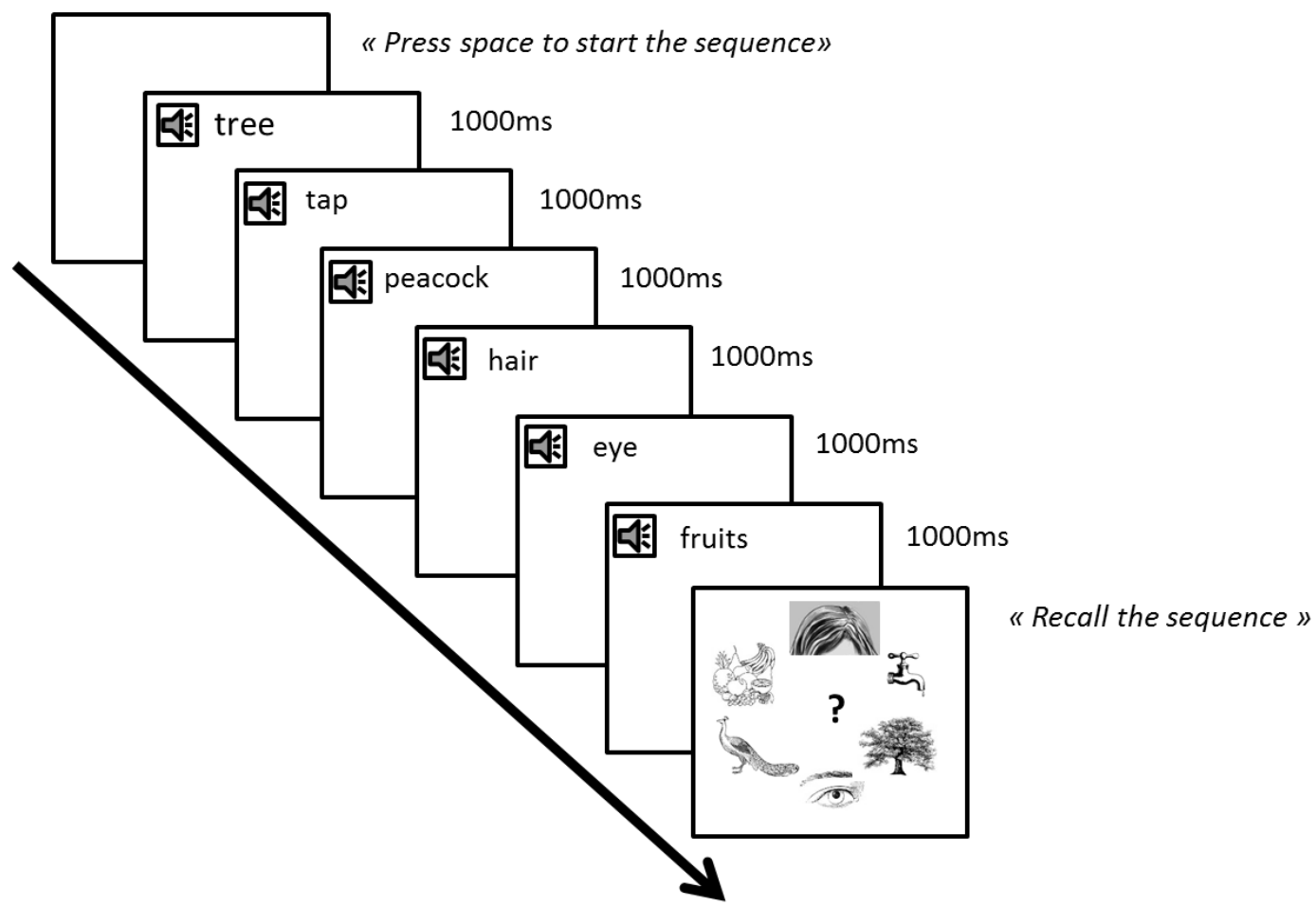

Figure 1. Trial procedure in the verbal Hebb task. The drawings were presented with random positioning on a circular arrangement around a central question mark, the positions being randomized on each trial. 


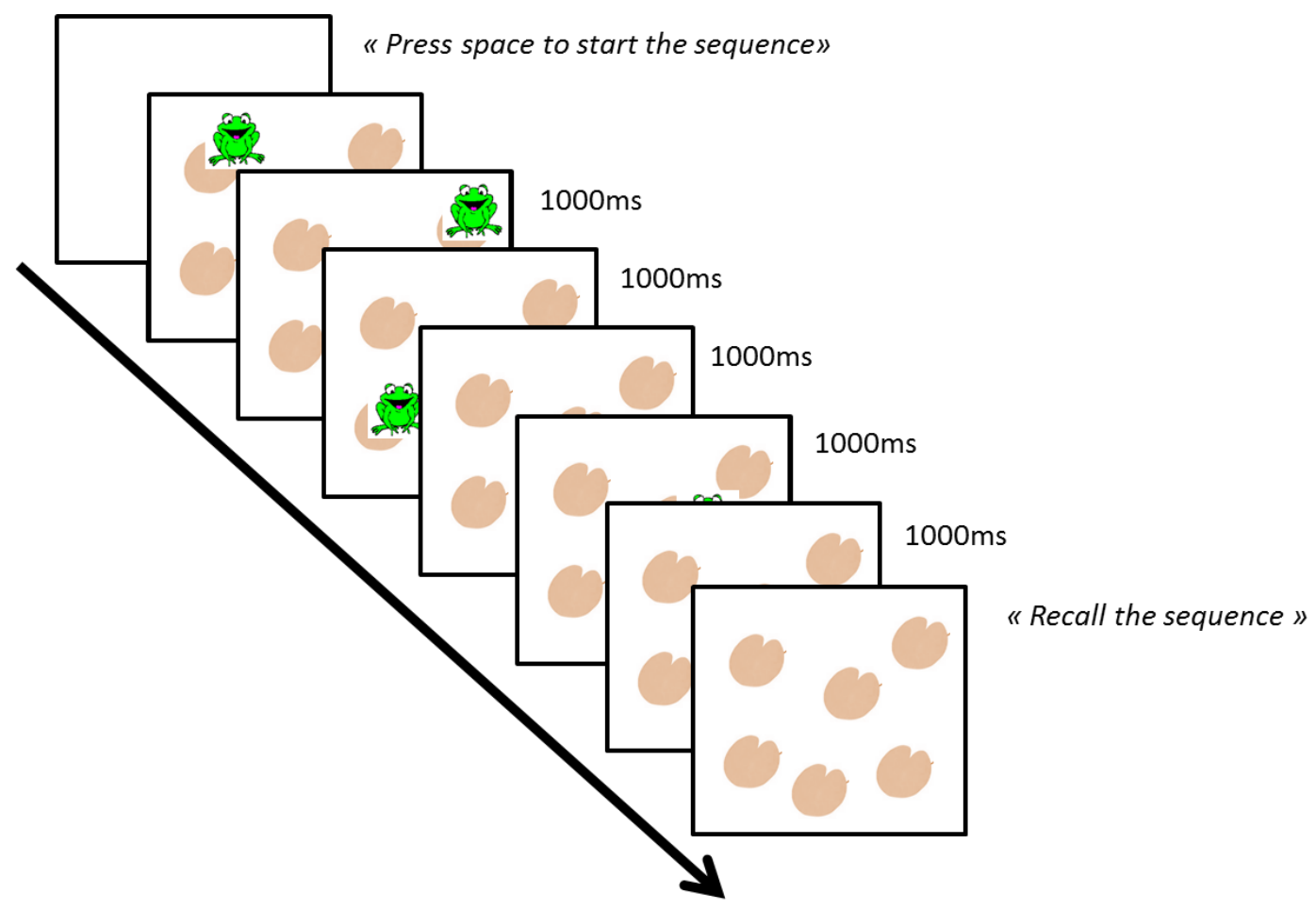

Figure 2. Trial procedure in the visuospatial Hebb task. 


\section{Verbal}

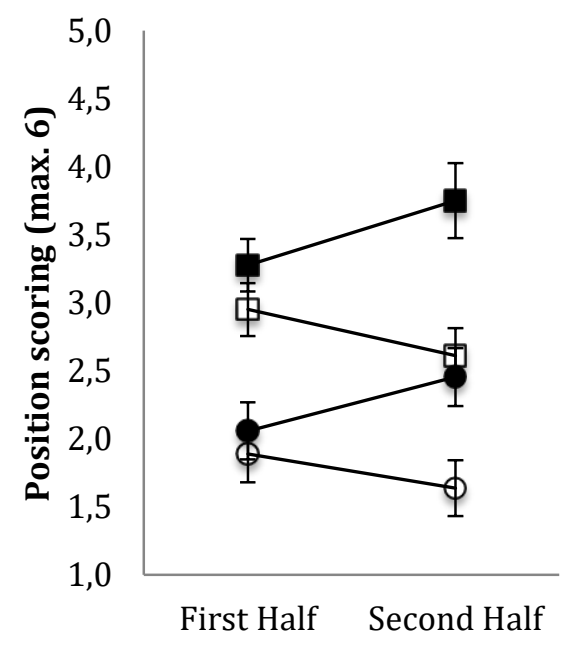

\section{Visuospatial}

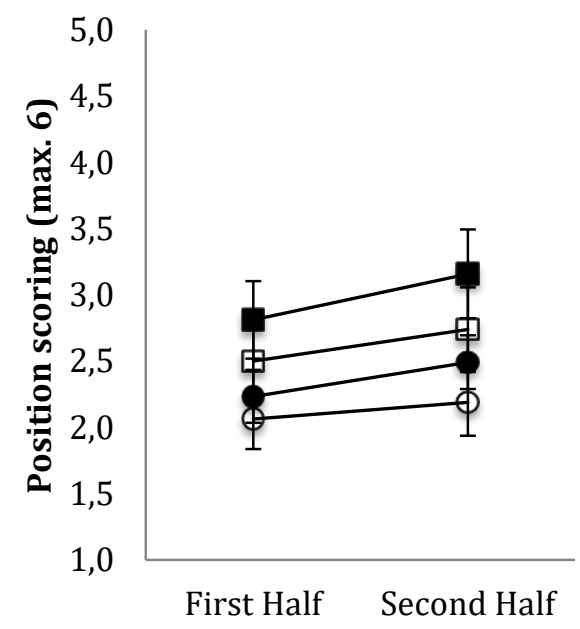

Figure 3. Mean correct recall (i.e., number of items recalled in correct serial position) as a function of repetition for the verbal (left) and visuospatial (right) Hebb task. Error bars denote $95 \%$ CI.

$\mathrm{M}_{\text {LITERATES }}=3.0,95 \% \mathrm{CI}[2.7,3.3]$ vs. $\mathrm{M}_{\text {ILLITERATES }}=2.1,95 \% \mathrm{CI}[1.8,2.4]$

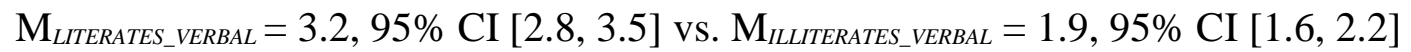

$\mathrm{M}_{\text {LITERATES_VISUOSPATIAL }}=2.8,95 \% \mathrm{CI}[2.4,3.3]$ vs. $\mathrm{M}_{\text {ILLITERATES_VISUOSPATIAL }}=2.2,95 \% \mathrm{CI}$

$[1.8,2.7]$ 


\section{SUPPLEMENTARY MATERIALS}

1A. Monosyllabic Hindi words (English translation in parentheses) and corresponding drawings; Participants were tested on their knowledge of these words using a wordto-picture matching task. A four-alternative forced-choice recognition task was used during which the Hindi words (recorded by the voice of a male Hindi speaker, noise cancelled and edited to have an equal length of $1000 \mathrm{~ms}$ ) were presented using headphones. For each trial, a word was presented auditorily together with four black and white drawings that appeared randomly in the quadrants of the screen. The participant was asked to click on the drawing that semantically corresponded to the presented word. Only one correct answer was possible. All literate and illiterate participants correctly identified all 32 words and 24 of these words were chosen as stimuli materials in the verbal Hebb task (see Supplementary 1B).

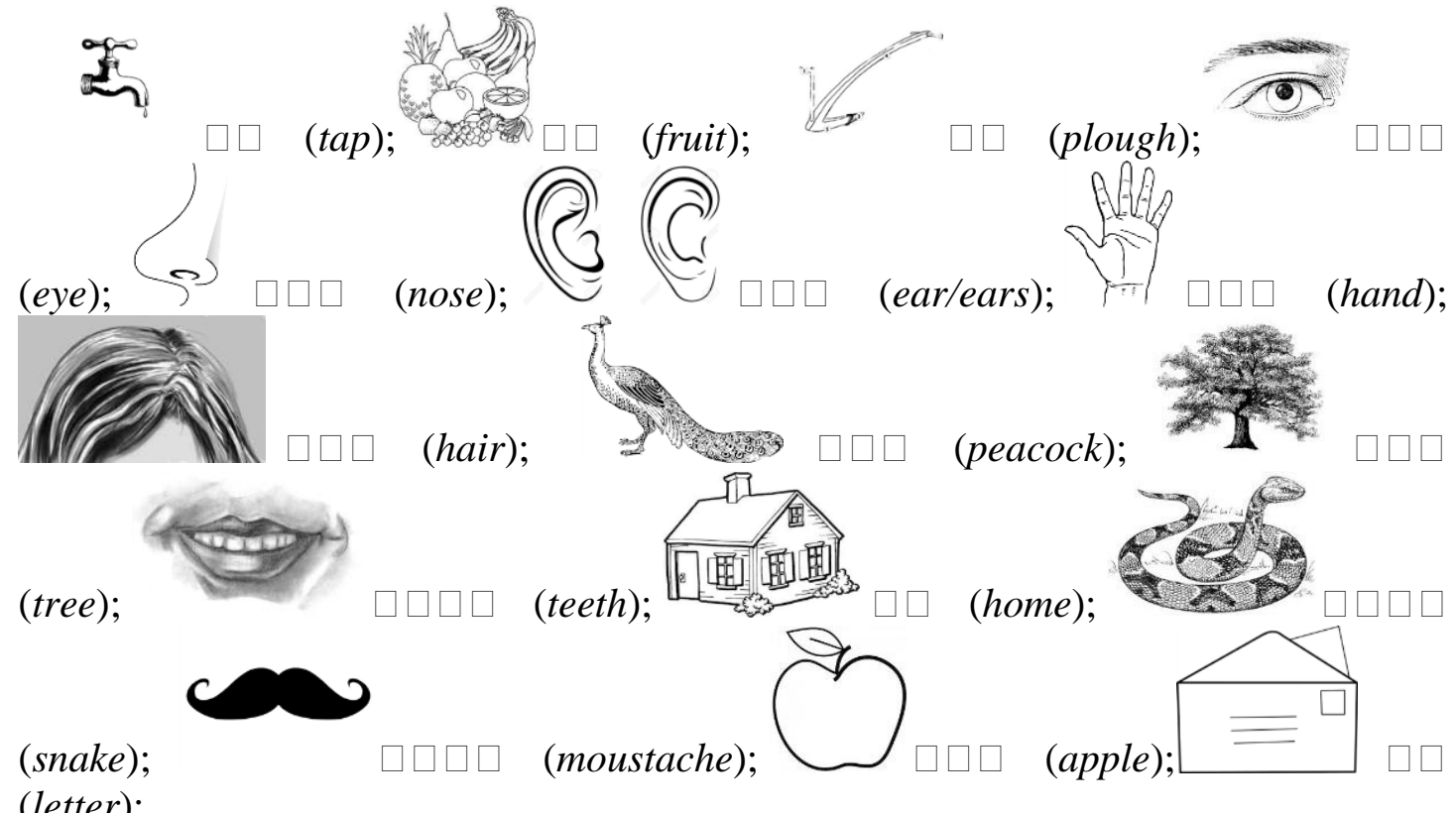



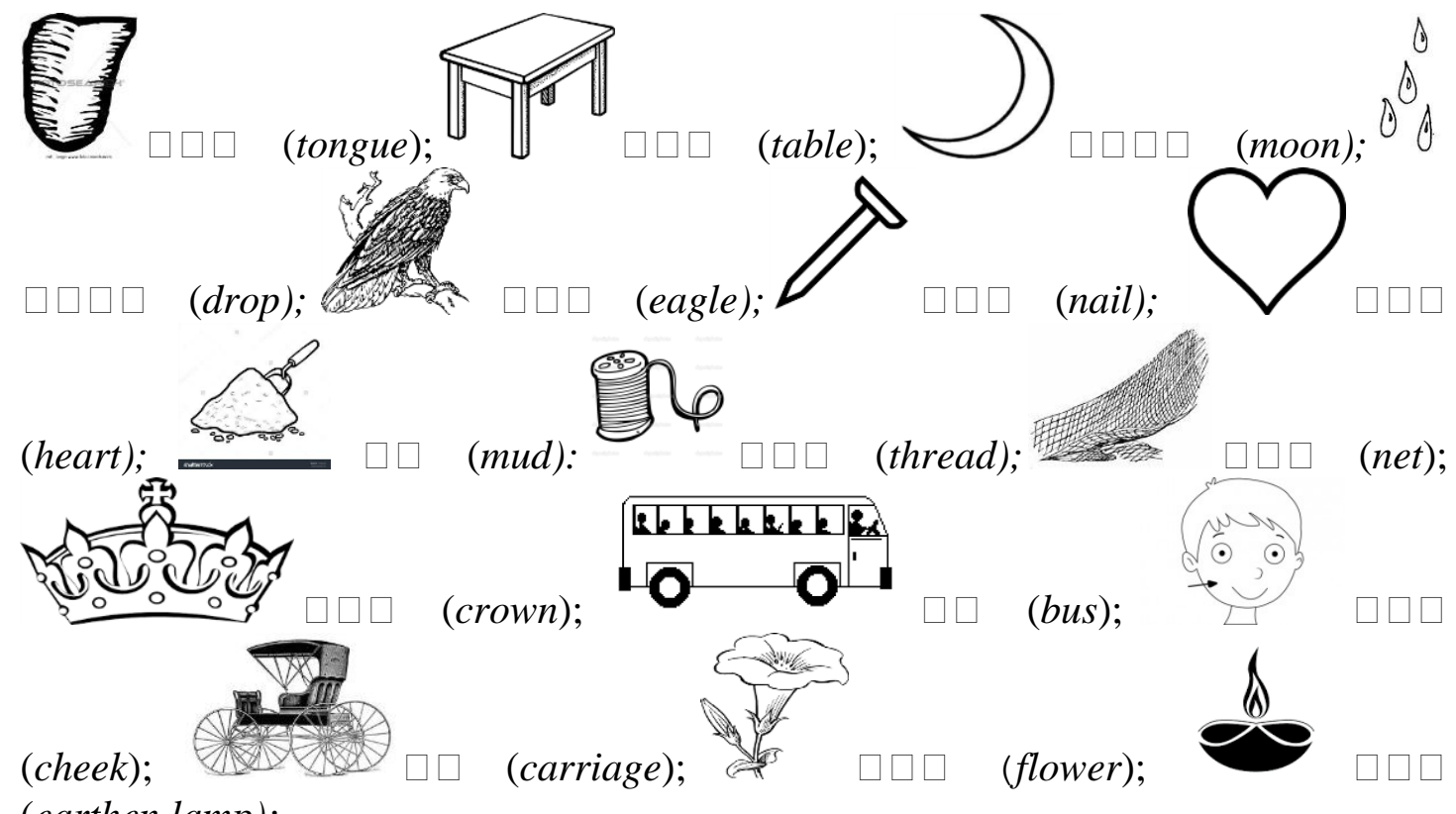
(earthen lamp); 
1B. The four different word sequences that were presented in the verbal Hebb learning task. To avoid list-specific effects, each of the four sequences was presented both as a Filler and a Hebb sequence across participants by using a Latin square design. For instance, Subject 1 received lists 1 to 4 as Filler, Hebb 1, Hebb 2, Hebb 3; Subject 2 received them as Hebb 3, Filler, Hebb 2, Hebb 1; Subject 3 as Hebb 2, Hebb 3, Filler and Hebb 1; and Subject 4 as H1, H2, H3 and Filler. For clarity, we have provided here the English translations of the monosyllabic Hindi words.

\begin{tabular}{ccccccc}
\hline & Position 1 & Position 2 & Position 3 & Position 4 & Position 5 & Position 6 \\
\hline Sequence 1 & tree & tap & peacock & hair & eye & fruits \\
Sequence 2 & nose & snake & hand & tongue & letter & home \\
Sequence 3 & eagle & ears & mud & plough & table & teeth \\
Sequence 4 & apple & thread & heart & drop & moon & moustache \\
\hline
\end{tabular}


1C. The four different pad configurations ( $x-y$ coordinates) that were created for the visuo-spatial serial recall task. The same Latin square design was used as for the verbal materials (Supplementary 1B).

\begin{tabular}{lcccccc}
\hline & Position 1 & Position 2 & Position 3 & Position 4 & Position 5 & Position 6 \\
\hline Sequence 1 & $(200,288)$ & $(597,270)$ & $(511,399)$ & $(291,345)$ & $(243,155)$ & $(403,164)$ \\
Sequence 2 & $(591,468)$ & $(200,288)$ & $(243,155)$ & $(597,270)$ & $(403,164)$ & $(291,345)$ \\
Sequence 3 & $(418,486)$ & $(591,468)$ & $(511,399)$ & $(200,288)$ & $(403,164)$ & $(597,270)$ \\
Sequence 4 & $(243,155)$ & $(403,164)$ & $(591,468)$ & $(597,270)$ & $(291,345)$ & $(511,399)$ \\
\hline
\end{tabular}


SUPPLEMENTARY ANALYSIS: Control for non-verbal intelligence

In order to control for the observed group difference in nonverbal intelligence (Table 1), we exploratory selected a small sample of twelve illiterate participants ${ }^{6}$ from the larger pool of illiterate participants (see participant information) that could be matched with twelve of the lowest performing literates in the present sample on initial scores of the Raven Progressive Matrices. Please note that an analysis of covariance on the main analysis is not recommended here since the statistical assumption of independence is violated (Miller and Chapman, 2001). An overview of the relevant characteristics for both groups is provided in Table A below. The two groups no longer matched on age, but were comparable on all other background variables, such as non-verbal intelligence and socio-economic status. The statistical results are presented below (Table B and C).

A (Bayesian) repeated measures ANOVA on these subgroups again revealed a main effect of Group with very strong evidence. Immediate serial-recall performance was better in literate $(\mathrm{M}=3.1,95 \% \mathrm{CI}[2.7,3.5])$ compared with illiterate people $(\mathrm{M}=$ $1.9,95 \%$ CI $[1.5,2.4])$. The interaction with Task Modality was no longer reliable but planned comparisons revealed a decisive group difference on immediate recall performance in the verbal task (Literates: $\mathrm{M}=3.2,95 \% \mathrm{CI}[2.8,3.6]$ vs. Illiterates: $\mathrm{M}$ $=1.9,95 \%$ CI $[1.5,2.3])$, and a weak group difference on immediate recall in the

\footnotetext{
${ }^{6}$ Six of these illiterate participants were kept from the sample in the present study.
} 
visuospatial task (Literates: $\mathrm{M}=3.0,95 \% \mathrm{CI}[2.4,3.6]$ vs. Illiterates: $\mathrm{M}=2.0,95 \% \mathrm{CI}$ $[1.4,2.7]$.

Further, there was a main effect of Sequence Type in favour of the repeating Hebb sequence. This interacted with Half: Planned comparisons showed larger improvements across halves for the Hebb sequence compared with the Filler sequence. The verbal Hebb effect further increased across the two halves, while this was not reliably the case for the visuospatial task. Hebb learning across both tasks did not differ as a function of Group. 
Table A. Participant characteristics (averages with range between brackets) for the nonverbal IQ-matched subgroups. Independent-samples t-tests were performed.

\begin{tabular}{lll}
\hline & Literates $(\mathrm{n}=12)$ & Illiterates $(\mathrm{n}=12)$ \\
\hline Age (in yrs) & $24.6(18-38)$ & $37.1(25-60)^{* *}$ \\
Sex & $\mathrm{F}=12, \mathrm{M}=0$ & $\mathrm{~F}=12, \mathrm{M}=0$ \\
Monthly income (in Rupees) & $2238(1333-4000)$ & $2211(1250-3250)$ \\
No. Of persons in family & $5.3(3-8)$ & $5.1(3-7)$ \\
No. Of earning family members & $1.3(1-3)$ & $1.5(1-2)$ \\
Family Income (in Rupees) & $11220(6.2 \mathrm{~K}-20 \mathrm{~K})$ & $10958(5 \mathrm{~K}-18 \mathrm{~K})$ \\
Years of schooling & $12.1(10-15)$ & $0.25(0-3)^{* * *}$ \\
Raven's Progressive Matrices, rs & $31 / 60(16-45)$ & $26 / 60(21-41)$ \\
& & \\
Word reading scores & $73 / 75(68-75)$ & $.83 / 75(0-7)^{* * *}$ \\
& & $1.8 / 44(0-14)^{* * *}$ \\
\hline
\end{tabular}


Table B. Repeated Measures ANOVA with factors Group (literate vs. illiterate), Task Modality (verbal vs. visuospatial), Sequence Type (Filler vs. Hebb), Half (first-half vs. second-half); $d f(1,22)$.

\begin{tabular}{|c|c|c|}
\hline Effects & $F$ & $n_{p}^{2}$ \\
\hline Group & $16.6 * * *$ & 0.429 \\
\hline Task Modality & $<1$ & -- \\
\hline Task Modality x Group & $<1$ & -- \\
\hline Verbal: Group & $25.67 * * *$ & 0.540 \\
\hline Visuospatial: Group & $4.7 *$ & 0.176 \\
\hline Sequence Type & $12.6^{* *}$ & 0.364 \\
\hline Sequence Type x Group & 1.30 & -- \\
\hline Half & 1.02 & -- \\
\hline Half x Group & $<1$ & -- \\
\hline Task Modality x Sequence Type & $6.23 *$ & 0.221 \\
\hline Task Modality x Sequence Type x Group & $<1$ & -- \\
\hline Task Modality x Half & $<1$ & -- \\
\hline Task Modality x Half x Group & 1.03 & -- \\
\hline Sequence Type x Half & $8.78 * *$ & 0.285 \\
\hline Hebb: Half & $10.3 * *$ & 0.318 \\
\hline Filler: Half & 1.08 & -- \\
\hline Sequence Type x Half x Group & 1.27 & -- \\
\hline Task Modality x Sequence Type x Half & $3.44^{\circ}$ & 0.135 \\
\hline Verbal: Sequence Type x Half & $8.19 * *$ & 0.271 \\
\hline Visuospatial: Sequence Type x Half & $<1$ & -- \\
\hline
\end{tabular}


Task Modality x Sequence Type x Half x Group

$<1$

${ }^{\circ} \mathrm{p}<.07, * \mathrm{p}<.05, * * \mathrm{p}<.01, * * * \mathrm{p}<.001$

Table3. Bayesian Repeated Measures ANOVA: Specific effects

\begin{tabular}{llll}
\hline Effects & $\mathrm{P}($ incl $)$ & $\mathrm{P}($ incl|data $)$ & $\mathrm{BF}$ inclusion \\
\hline Group & 0.114 & 0.531 & 51.491 \\
Task Modality x Group & 0.299 & 0.168 & 0.478 \\
$\quad 0.263$ & 0.600 & 425.970 \\
$\quad$ Verbal: Group & 0.263 & 0.573 & 2.077 \\
$\quad$ Visuospatial: Group & 0.114 & 0.005 & 0.506 \\
Sequence Type x Half x Group & & & \\
Task Modality x Sequence & 0.006 & $3.242 \mathrm{e}-6$ & 0.383 \\
Type x Half x Group & & &
\end{tabular}

Note: $\mathrm{P}(\mathrm{incl})=$ prior inclusion probability; $\mathrm{P}($ incl $\mid$ data $)=$ posterior inclusion probabilities; $\mathrm{BF}_{\text {inclusion }}=$ change from prior to posterior inclusion odds 